\title{
La crítica de Del Noce a Maritain y los orígenes intelectuales del catolicismo de izquierda $^{1}$
}

\section{Carlos Hoevel*}

Pontificia Universidad Católica Argentina carlos_hoevel@uca.edu.ar

\section{Revista Cultura Económica}

Año XXXIX $\bullet \mathrm{N}^{\circ} 102$

Diciembre 2021: 101-118

https://doi.org/10.46553/cecon.39.102.2021.p101-118

Resumen: Si bien Augusto Del Noce se reconoce discípulo y admirador de Maritain, en su famoso libro El problema del ateísmo, realiza una fuerte crítica de su maestro a raíz de la aceptación por parte de este último de ciertas tesis sociales y económicas del marxismo. Atribuyendo la causa de esta postura de Maritain a una falla central en su visión de la filosofía y la historia modernas, Del Noce acusará a Maritain de introducir involuntariamente en el pensamiento social católico un germen perfectista-utópico incompatible con el cristianismo. A partir de esta crítica, el filósofo italiano dejará pistas en sus escritos acerca de las influencias en otros pensadores cristianos de esta apertura maritainiana al marxismo. En tal sentido, el pensamiento de Del Noce resulta un punto de partida eficaz para explorar la génesis intelectual del catolicismo de izquierda tanto europeo como latinoamericano de las últimas décadas con influencia hasta nuestros días.

Palabras clave: Del Noce; Maritain; Marxismo; Catolicismo; Izquierda

\section{Del Noce's critique of Maritain and the intellectual origins of left Catholicism}

Abstract: Although Augusto Del Noce recognizes himself as a disciple and admirer of Maritain, in his famous book The Problem of Atheism, he makes a strong criticism of his teacher as a result of the latter's acceptance of certain social and economic theses of Marxism. Attributing the cause of Maritain's position to a central flaw in his view of modern philosophy and history, Del Noce will accuse Maritain of inadvertently introducing into Catholic social thought a perfectist-utopian germ incompatible with Christianity. From this criticism the Italian philosopher will leave clues in his writings about the influences on other Christian thinkers of this Maritainian openness to Marxism. In this sense, Del Noce's thinking is an effective starting point for exploring the intellectual genesis of left-wing Catholicism, both in Europe and in Latin America, in recent decades with influence to this day.

* Recibido: 05/12/2021 - Aprobado: 20/12/2021 
Keywords: Del Noce; Maritain; Marxism; Catholicism; Left

\section{Introducción: Del Noce discípulo de Maritain}

Uno de los méritos del filósofo italiano Massimo Borghesi (2011) ha sido el de evidenciar los vínculos entre Augusto Del Noce y Jacques Maritain, dos filósofos que no se terminan de entender cuando se los considera por separado. Maritain es conocido fundamentalmente por dos razones: haber sido quizás el mayor difusor contemporáneo de la filosofía tomista, y haber promovido la aceptación final de la democracia por parte de la Iglesia. Sobre Augusto del Noce se conoce mucho menos. Para sintetizar su aporte se podría decir que es el filósofo que modificó la visión de la filosofía moderna (Del Noce: 1965, 2010) y pronosticó los dos eventos históricos más importantes sucedidos desde 1989 a esta parte: por un lado, la descomposición y caída del marxismo (Del Noce, 2004) y, por el otro, el advenimiento de la sociedad tecnológica actual (Del Noce, 2015).

Pero ¿qué tienen que ver ambos filósofos entre sí y qué relación tiene su vínculo con los orígenes del catolicismo de izquierda que propongo en el título?

El vínculo de Del Noce con Maritain se remonta a la juventud del primero en la década del 30. Siendo un joven filósofo católico, Del Noce será uno de los primeros en leer a Maritain en Italia. Dedicado a analizar las ideas del célebre libro Humanismo integral (1936) de Maritain, Del Noce quedará deslumbrado. Formando parte del frente católico antifascista italiano todavía minoritario, el filósofo de Turín recibirá con entusiasmo el rechazo de Maritain a la postura de muchos católicos que interpretaban a los regímenes fascistas como potenciales aliados de la Iglesia contra el iluminismo y el liberalismo modernos. De este libro asimilará también la audaz propuesta maritainiana de romper con la postura católica tradicional de rechazo a la democracia moderna.

En efecto, en contacto con la obra de Maritain, Del Noce asumirá la idea de que la democracia y los derechos modernos tienen raíces cristianas y que, por tanto, la Iglesia debe ponerse del lado de aquellos contra los totalitarismos fascistas. Maritain será así para Del Noce el autor fundamental que le permitirá superar el prejuicio dominante en la Iglesia de aquel momento que casi obligaba al creyente a sostener una oposición frontal a la 
modernidad -como la que propiciaban los tradicionalistas católicos antimodernos. A partir de su lectura de Maritain, Del Noce adoptará una postura de apertura a la modernidad, asimilando todo lo que pudiera encontrarse de bueno y compatible con la tradición cristiana dentro de ella.

Sin embargo, habrá una diferencia central entre ambos filósofos que se irá develando con el tiempo y que, llamativamente, no aparece del todo explicitada en el texto de Borghesi. Esta consistirá en la diferente postura que irá tomando Del Noce en relación al planteo maritainiano sobre la filosofía moderna, el liberalismo y, en especial, sobre el marxismo. Esta última cuestión, que será precisamente el objeto de crítica por parte de Del Noce a Maritain, tendrá no solo gran relevancia para entender las diferencias que hubo entre ellos, sino también, y sobre todo, para la comprensión de algunas tendencias y conflictos que se darán en la Iglesia y en la sociedad en general en las décadas sucesivas.

\section{La crítica delnociana a Maritain: el germen perfectista}

La mencionada crítica de Del Noce a Maritain puede reconocerse con toda claridad en las páginas del ensayo del primero sobre Teismo y ateismos políticos de 1962, recogido en su famoso libro Il problema dell'ateismo (1964). Cuando se consulta ese importante ensayo, se puede ver que el argumento central de Del Noce radica allí en la idea de que, más allá de las dos posturas del tradicionalismo integrista antimoderno y del modernismo progresista que caracterizaban en aquel tiempo al catolicismo, existía una tercera opción que él veía surgir subrepticiamente a partir de la década del 30 en Maritain, y que se continuaría en autores vinculados con este (escribe en 1962), que describirá como "una línea de menor resistencia al modernismo que finalmente terminará por ceder al modernismo” (Del Noce, 2010: 520).

Pero ¿̇en qué consiste esta "menor resistencia al modernismo" que Del Noce ve en Maritain? Para él nace del hecho de que Maritain acepta los valores de la política moderna (libertades, democracia), rechazando la oposición frontal a la democracia de los tradicionalistas, pero cayendo también en la tentación de aceptar algunos elementos de un idealismo socialista cristiano de tendencia utópica -formulado en la clave de su proyecto de una nueva cristiandad- que basará en elementos socioeconómicos tomados del marxismo.

En efecto, de acuerdo a Del Noce, si bien Maritain rechaza de plano el materialismo y el ateismo del marxismo (Cottier et al., 1979), 
ha admitido no solamente la noción de clase, sino también el dualismo exclusivo del proletariado y la burguesía, la unidad del proletariado, el acuerdo del cristiano y del marxista en relación a la existencia de clases y de su conflicto; en suma, las nociones que tienen significado solo dentro del materialismo histórico (Del Noce, 2010: 526).

De este modo, según Del Noce, Maritain "abre el camino" (esta es su expresión exacta), no en todo sino en una parte de su pensamiento y de modo más o menos involuntario, a lo que Del Noce llamará -con expresión rosminiana- el "germen perfectista" de la visión de la historia y de la sociedad. En efecto, de acuerdo a Del Noce, el perfectismo es

definido exactamente por Rosmini como "aquel sistema que cree posible lo perfecto en las cosas humanas y que sacrifica el bien presente a la imaginaria perfección del futuro", con las consecuencias de la supresión de la libertad [...] la desvalorización de la historia pasada y la deificación de la historia futura, la necesidad de considerar el pecado original como un residuo eliminable y la reducción del individuo a sus relaciones sociales (Del Noce, 2010: 520, nota 8).

En tal sentido, para Del Noce este perfectismo tomará más tarde la forma, en los representantes del catolicismo de izquierda que profundizarán y extremarán la brecha abierta por Maritain, de un "neomodernismo entendido, no más al modo del viejo modernismo, como alianza del catolicismo y las formas de pensamiento ligadas a la reacción idealista contra la ciencia de los años sucesivos al 90 [...] sino con el marxismo [...]”. (Del Noce, 2010: 574).

Por lo demás, Del Noce se preguntará por qué Maritain cede de esta manera frente al marxismo, permitiendo de algún modo la entrada de su germen perfectista-utópico -y en el fondo ateo- en el corazón del catolicismo. Su respuesta será que esto sucedió porque el pensamiento de Maritain tiene, a su criterio, una falla central en su filosofía de la historia que procede de una falla aún más profunda en su visión de la filosofía moderna.

\section{La puerta abierta de Maritain al marxismo: entre el clima de época y los problemas de su concepción de la historia moderna}


Existen ciertamente una serie de circunstancias históricas que podrían aducirse en el contexto de la trayectoria vital, intelectual, política y eclesial de Maritain que podrían en parte explicar su acercamiento -en gran medida involuntario- al marxismo tal como lo describe y critica Del Noce.

Una primera circunstancia, podría ser su amistad con Peguy (Bressolette, 1997), obviamente muy juvenil si pensamos que la trágica muerte de este último se produce en los inicios de la guerra de 1914. Más allá de sus desavenencias, generadas a raíz del drama personal de Peguy y de la dureza del muy joven Maritain, discípulo de Bloy y adherente a la ultraderechista Action Francaise, lo cierto es que el socialismo del puro y místico Peguy seguramente ha sido una poderosa influencia sobre Maritain. Sin embargo, también hay que decir que dicho socialismo era algo absolutamente distinto al socialismo marxista de tipo materialista. Más bien se trataba de lo que Del Noce llamará un socialismo ético caracterizado por una visión de solidaridad social basada en el amor cristiano a los más necesitados, pero con un respeto absoluto por la libertad individual. De hecho, Del Noce sostendrá en otros textos que a los socialistas éticos de esta clase ni siquiera les debería caber el nombre de socialistas (Del Noce, 2010: $526)$.

Una segunda circunstancia, esta ya sí mucho más concreta en su relación con el marxismo, será el clima de izquierda que se vive en el catolicismo personalista francés (Mounier y la revista Esprit en general), decantado y agudizado por la guerra de España (Curtis, 1997). Como se sabe, Maritain participará de Esprit, y escribirá Humanismo integral precisamente en medio de ese clima. ¿De qué modo se relacionan las páginas receptivas en relación a muchos elementos del marxismo en el Manifiesto al servicio del personalismo de Mounier y en Humanismo integral de Maritain, ambas obras publicadas en el mismo año clave de 1936? Es difícil saberlo. De hecho, no parece una tarea sencilla desentrañar cuáles de las diversas tendencias presentes en Esprit fueron realmente neomodernistas/perfectistas o producto de la reacción al entorno fascista e integrista de la época. Por otro lado, identificar de qué modo estas tendencias fueron aceptadas, rechazadas, toleradas o incluso inintencionalmente fomentadas por Maritain parecería ser una tarea aún más compleja ${ }^{2}$.

No obstante, de acuerdo a Del Noce, existen razones mucho más profundas que las de las circunstancias históricas para explicar la apertura al marxismo de Maritain. Estas tendrán que ver con la visión que este último tiene de la modernidad. En efecto, si bien Maritain supera al tradicionalismo 
en su aceptación de la democracia moderna, sigue atado, de acuerdo a Del Noce, a su esquema antimoderno en el plano filosófico. En tal sentido, Maritain no solo habría rechazado el planteo de la filosofía moderna en su versión inmanentista -empirista, racionalista e idealista-, sino también en todo lo compatible con la filosofía cristiana existente en varios de los principales filósofos modernos (tales como Descartes, Leibniz, Pascal, Malebranche, Gerdil o Rosmini). De este modo, Maritain seguiría en esto el rechazo frontal de los neoescolásticos a los filósofos cristianos modernos considerados como ontologistas- y por esta razón sería partidario, al igual que los primeros, de la inevitable necesidad de un regreso a las fuentes del tomismo medieval, con la única modificación de la incorporación de un lenguaje de estilo existencial3.

Por lo demás, ese rechazo in toto de Maritain de la filosofía moderna tendrá, según Del Noce, otros componentes concomitantes vinculados a su visión de la historia socioeconómica moderna. De hecho, Del Noce mostrará el modo en que Maritain interpreta incluso las ideas teológicas de inspiración cristiana contenidas en los tratados de filósofos racionalistas de la edad barroca, como Descartes o Malebranche y los demás antes mencionados, no solo como el resultado de una especulación intelectual, sino como el reflejo ideológico del orden individualista liberal, en el fondo ateo, que en su opinión buscó imponer la burguesía de la primera modernidad. De esta manera, para Maritain la filosofía moderna resultaría ser la expresión, en clave intelectual, del espíritu individualista y subjetivista de la burguesía liberal (Del Noce, 2010: 530-531).

En tal sentido, de acuerdo a Del Noce, si bien Maritain aceptará la democracia y las libertades políticas, no encontrará el modo de insertarlas dentro de una tradición liberal que ve unida a una filosofía moderna ligada a la mentalidad individualista y potencialmente atea de la burguesía. A partir de la asunción de esta tesis, "no es posible, según Del Noce, escapar a las consecuencias”. En efecto, en su opinión,

una vez introducido este concepto clasista se vuelve imposible limitarlo. El socialismo representa una instancia superior a aquella del liberalismo [...] Pero así el pasaje de la posición reaccionaria a aquella democrática tiene la consecuencia en el interior del horizonte histórico de Maritain, de transcribir de una cierta manera dentro del tomismo la visión marxista de la historia moderna (Del Noce, 2010: 531). 
Por esta razón, según Del Noce, Maritain terminará por adoptar la perspectiva de una lectura de la historia del pensamiento que tiene como punto de partida el tomismo propio de la cristiandad medieval y como punto de llegada el personalismo comunitario de la nueva cristiandad que ve en buena medida, junto con otros miembros del grupo de Esprit, como el resultado de una superación -por así decirlo- socialista-cristiana del largo tramo irrescatable de la modernidad liberal burguesa.

\section{Las influencias sobre el grupo Esprit, la Escuela de Le Saulchoir, el movimiento Economía y Humanismo y el catolicismo italiano de izquierda}

Las consecuencias negativas de este pequeño gran acto de apertura de Maritain al marxismo serán, de acuerdo a Del Noce, amplias y profundas para la Iglesia y en particular para la teología y el pensamiento social católico de la posguerra. Empezando por Francia, en donde especialmente el epicentro será la Revista Esprit, que acompañará “desde atrás” la alianza y amistad entre católicos y comunistas en la Resistencia durante la Segunda Guerra Mundial, que llevará a Mounier a ser arrestado por el régimen de Vichy, convirtiéndolo en el futuro ícono del socialismo cristiano e inspirador del diálogo con el marxismo de las siguientes décadas tan criticado por Del Noce4.

Por otra parte, también es posible verificar cómo la apertura de Maritain al marxismo también afectará, si seguimos las pistas que nos da Del Noce más allá de sus textos, los orígenes de la más importante corriente teológica del siglo XX, que habría de marcar el rumbo de la Iglesia a partir del Concilio Vaticano II: la Nouvelle Théologie. De hecho, la puerta abierta por Maritain dejará su impronta sobre todo en una de las dos grandes ramas de la Nouvelle Théologie: la de los miembros de la llamada Escuela de Le Saulchoir, especialmente los destacados teólogos dominicos MarieDominique Chenu e Yves Congar (Chenu, 1985).

En efecto, Chenu y Congar -considerados dos de los más importantes teólogos del siglo XX, de enorme influencia en el Concilio- fueron iniciadores de una teología basada en un tomismo existencial, abierto a la historia y a la Escritura, y a una lectura crítica de la sociedad. Pero ambos se destacarán también como figuras fuertemente involucradas en el devenir históricopolítico de su tiempo. Habiendo sido combatientes en la Resistencia, serán asimismo discípulos de Maritain y seguirán su tesis sobre la necesidad del rescate de ciertos aspectos del marxismo desarrollada en Humanismo integral, obra que ambos citarán profusamente. A partir de esta apertura 
maritainiana, ambos teólogos desarrollarán una lectura teológica del proceso económico y social ensayando un diálogo entre la perspectiva bíblica y la marxista.

Especialmente enfocados en la gran cuestión del trabajo (Chenu, 1960), intentarán, de hecho, llevar esta visión al nivel de la praxis social por medio de la fundación del movimiento de los sacerdotes obreros. La influencia de la puerta abierta por Maritain al marxismo sobre los principales representantes de esta rama de la Nouvelle Théologie llegará así a convertirse, por diversos caminos, en la base del diálogo francés y europeo entre el catolicismo y el marxismo de los años 50 y 60, impactando especialmente en la teología de la liberación latinoamericana, que los propios Chenu y Congar considerarán en buena medida un punto de llegada crucial de su propio itinerario teológico5.

Como una rama económico-social vinculada a la Escuela de $L e$ Saulchoir -y a la apertura a ciertas tesis del marxismo propiciada por Maritain- se destacará también el grupo de Economie et Humanisme, fundado en Marsella en 1941 y continuado luego en Lyon por el dominico Louis Joseph Lebret (1897-1966), con quien colaborarán personalidades notables como el economista Francois Perroux, entre muchos otros. Como se sabe, Lebret fue una figura extraordinaria en el campo de los estudios sociales: dirigirá múltiples investigaciones y aportes prácticos en el campo de la organización laboral y el urbanismo (Houée, 1997). Actuará no solo en Francia, sino también en América latina, en donde trabajará personalmente en diversos proyectos en Brasil, Colombia, Chile y Uruguay, convirtiéndose en un referente mundial en la célebre cuestión del desarrollo, especialmente de los países del llamado tercer mundo. Su vínculo estrecho con Montini lo convertirá finalmente en asesor en el Concilio e inspirador central de la encíclica Populorum Progressio.

En cuanto a su visión filosófico-social, Lebret será primero inspirado por un comunitarismo de estilo corporativista muy cercano al régimen de Vichy, para después de la Liberación abrirse al diálogo con el marxismo bajo la influencia del maritanismo de izquierda del momento. Una figura clave en este sentido, será Henri Desroche (o Desroches como él se hacía llamar) quien, habiendo estudiado en Le Saulchoir, escribirá Signification du marxisme (1949), una de las obras más polémicas de la época, cuya sombra acompañará toda la obra de Lebret desde los inicios de Economie et Humanisme. De este modo, si bien Lebret nunca será marxista manteniéndose siempre dentro de una postura que podríamos llamar 
desarrollista cristiana (Lebret, 1958), participará también, a su manera, de este primer movimiento maritainiano de apertura del catolicismo hacia el marxismo.

La influencia de esta apertura iniciada en Francia por Maritain, se hará sentir fuertemente también entre los católicos y protestantes de otros países europeos, como Bélgica (especialmente la Universidad de Lovaina), Alemania (en donde influirá en los orígenes de la teología política en Bonhoeffer y luego en J. B. Metz) y también en Italia. De hecho, en este último país, un protagonista de dicho momento filomarxista entre los católicos durante la guerra, será el propio Del Noce. Tal como señala Borghesi (2011), con la lectura de Humanismo integral, el gran filósofo italiano se convertirá en un maritainiano y en un socialista cristiano al mismo tiempo. Pero esta no será solo una veleidad personal. Constituirá el camino de cientos de jóvenes católicos de izquierda de la posguerra inspirados en Maritain de donde surgirá una pléyade de intelectuales y actores políticos como Dossetti, Rodano, Balbo y tantos otros precursores del potente catolicismo maritainiano italiano de izquierda que se enfrentará luego, dentro de la DC, al maritainismo liberal de Sturzo, De Gasperi y del propio Del Noce quien, a partir de la década del 50, comenzará a cuestionarse fuertemente la apertura de Maritain al marxismo.

Por lo demás, dicho maritainismo de izquierda será el trasfondo, entre otras cosas, del diálogo y el nuevo compromiso entre católicos y comunistas ya mencionado, que inspirará también la segunda etapa del gobierno de la democracia cristiana italiana a partir de los años 6o (Fanfani- Moro), oficiando también de telón de fondo de la visión socioeconómica de una parte de los padres conciliares y de algunos momentos y aspectos de la enseñanza social del pontificado de Montini.

\section{La postura de la Escuela de Lyon y la crítica profética de Gastón Fessard}

Entre tanto, los miembros de la otra rama de la Nouvelle Théologie -como los jesuitas de Lyon-Fourvière (Avon, 2005), Henri De Lubac, Jean Daniélou, Henri Bouillard, Gastón Fessard, Hans Urs von Balthasar y otras figuras, como el historiador Henri Marrou, a las que también hará referencia Del Noce (2010) - se moverán en una dirección muy diferente al entonces ascendente maritainismo de izquierda. Ciertamente todos estos pensadores compartirán con los teólogos de Le Saulchoir la inspiración de una teología mucho más vinculada a la Escritura, a los Padres y a la historia. En oposición a un 
tomismo racionalista y ahistórico desarrollado por gran parte de la neoescolástica dominante en la época -con la figura de Garrigou-Lagrange a la cabeza- desarrollarán una teología en que lo natural y lo sobrenatural, lo teológico y lo histórico-social formarán un entretejido mucho más estrecho.

Sin embargo, y a pesar de estas coincidencias, ninguno de los representantes de Lyon-Fouvière seguirá el camino de una apertura hacia el marxismo emprendido por varios de los pensadores de la otra gran rama de la Nouvelle Théologie. Inspirados tanto en Blondel como en Maritain, se moverán, como estas dos grandes figuras, dentro de una línea de pensamiento claramente antifascista y antiintegrista y de crítica de una Iglesia entendida como una institución puramente jurídica aislada de la sociedad. Sin embargo, su cercanía a lo histórico-social no los llevará, como los de Le Saulchoir, a incorporar conceptos de la visión marxista de la historia socioeconómica, tal como lo había de algún modo alentado Maritain. De hecho, en especial Fessard, Marrou y von Balthasar, se expresarán en términos muy cercanos a la posición delnociana de negativa a cualquier diálogo con el marxismo, y por tanto también a sus posibles derivaciones teológicas y pastorales.

Tal vez el único punto de duda que tendrá Del Noce sobre la influencia del maritainismo de izquierda en estos autores será a raíz de la interpretación del marxismo realizada por De Lubac en El drama del humanismo ateo (1944). En efecto, De Lubac citará a Maritain muchas veces en sus obras, repitiendo su misma tesis en cierto modo ambigua con relación al significado moral del marxismo, con el agregado, que influirá a su vez, según Del Noce, en Maritain, de considerarlo justificado por la supuesta base bíblica de este último. Ciertamente, este tema merecería un análisis aparte pero básicamente se podría afirmar que Del Noce cree que De Lubac, a quien admira y con quien comparte su visión del ateísmo moderno, realiza sin embargo una interpretación errada del ateísmo de Marx. De hecho, de acuerdo al pensador italiano, De Lubac juzgará equivocadamente dicho ateismo como un resto extrínseco a su pensamiento -proveniente de la influencia de Feuerbach- perfectamente separable de ciertos aspectos éticos y religiosos de la visión social y económica marxista, considerados de origen bíblico, que podrían así ser asumidos por el pensamiento social católico ${ }^{6}$.

Está claro que esta lectura benevolente de Marx por parte de De Lubac -que por otra parte nunca será llevada a la práctica por él en la acción político social- no fue nunca precisamente la causa de la potente apertura hacia el marxismo entre los jesuitas en los años sucesivos, como sucedió, por ejemplo, 
en los casos de la revista Action Populaire, dirigida por el Padre Bigo y luego también especialmente en Alemania, con las figuras de Rahner y Metz, y más tarde incluso en las más altas esferas de la Compañía. Pero también es cierto que para Del Noce la postura de De Lubac no resultará precisamente una ayuda para abonar su convicción de que el ateismo es esencial al marxismo y por tanto este último sería una ideología completamente incompatible incluyendo sus aspectos históricos y económico-sociales- con el cristianismo. En tal sentido, Del Noce sostendrá esta posición intransigente con relación el marxismo hasta el final, permaneciendo indiferente a las opiniones de una importante mayoría que, en el fragor de los años sesenta, descalificará esa clase de intransigencia denominándola, peyorativamente, como "una lectura monolítica del marxismo".

El pensador del grupo de Lyon con quien Del Noce sentirá la mayor cercanía y afinidad, será el filósofo y teólogo jesuita Gastón Fessard. De hecho, probablemente haya sido a través del propio Fessard de quien Del Noce tomará conciencia por primera vez del error de Maritain que suscitará luego su propia crítica. En efecto, en su libro De L'Actualité Historique (1959), Fessard había ya salido al cruce de modo frontal antes que el propio Del Noce, a los intentos de Maritain de introducir las tesis históricas y sociales del marxismo -especialmente la misión histórica del proletariado, el rechazo sin matices a la burguesía moderna, y el conflicto entre clases- en la interpretación cristiana del problema social. Admitiendo el aspecto positivo de la sensibilidad tanto de Maritain como de los teólogos de Le Saulchoir (en especial de Chenu) frente "a la novedad de los problemas que presentan a la filosofía y a la teología tradicionales las exigencias de nuestro tiempo", Fessard los acusará, sin embargo de utilizar "fórmulas ambiguas" que terminarán incorporando en la visión filosófico-teológica cristiana de la historia, elementos esencialmente incompatibles provenientes del marxismo (Fessard, 1959: 290).

De este modo, aunque Fessard, al igual que Del Noce -quien lo cita abundantemente- atenuará la responsabilidad de Maritain sobre los graves efectos que su casi "involuntaria" apertura al marxismo produciría después en la Iglesia, le atribuirá sin embargo un rol clave como agente intermediario:

Escribiendo estas frases en 1936, Maritain no podía evidentemente prever que su contenido, simplificado en lugar de profundizado, sería retomado por el progresismo católico [...] Pero es importante mostrar a través de qué intermediario esta idea doblemente 
ambigua se abrió camino hacia el progresismo al mismo tiempo que este último también la amplió todavía más (Fessard, 1959: 191).

\section{La deriva latinoamericana del maritainismo y la génesis de la teología de la liberación}

La mención de la figura de Gaston Fessard, sin duda decisiva como una de las fuentes principales de la crítica de Del Noce a Maritain, nos da pie para mencionar, aunque sea brevemente, el rol de Maritain en la génesis de una corriente teológica que hoy es considerada casi consustancial a los latinoamericanos: la teología de la liberación. De hecho, no es algo muy conocido que Fessard, tan admirado por algunos autores estrechamente vinculados al pensamiento liberacionista (cfr. Scannone, 1982), fue probablemente el primero, más agudo y lapidario crítico de la teología de la liberación en el momento más álgido de sus orígenes (Fessard, 1979). De hecho, la describe, muy duramente, como una "ilusión" y una "perversión". Pero concentrémonos en el rol de Maritain en este último episodio de sabor más local para quienes vivimos en esta región del mundo.

Las recepciones de Maritain en América Latina son sin duda variadas. Van desde los grupos integristas y nacional-católicos que lo leen antes de su giro de 1936 en Humanismo integral, pasando por los diferentes grupos de social-cristianos, demócrata-cristianos y católicos liberales que lo siguen luego de su cambio de postura en relación a la democracia y las libertades modernas, hasta los que, a partir de sus expresiones de apertura al marxismo, se volcarán hacia posiciones afines al ya citado maritainismo perfectista de izquierda al que nos venimos refiriendo.

En un importante artículo sobre las fuentes francesas de la teología de la liberación en Brasil, el sociólogo liberacionista-marxista Michael Löwy (al que probablemente se conozca más en la academia como estudioso de Walter Benjamin), relata el momento histórico que prepara el nacimiento de dicha teología al mismo tiempo que echa luz sobre la influencia de la filosofía francesa, y en particular de Maritain, sobre los fundadores del liberacionismo latinoamericano (Löwy, Garcia-Ruiz, 1997). Es cierto que en los temas sociales y económicos finalmente terminarán influyendo mucho más a autores como Mounier, Lebret o Calvez quienes, siguiendo también a Maritain, rechazarán la filosofía materialista de Marx, pero aceptarán muchas de sus tesis sociológicas. Pero el hecho histórico es que, en el ambiente eclesial latinoamericano de la posguerra, la bandera verde al diálogo con el marxismo levantada por Maritain -considerado, por lo menos hasta fines de los años 
cincuenta, como la figura más influyente de la filosofía cristiana - tendrá un impacto mucho más amplio que el pensamiento de Mounier o de cualquier otro pensador cristiano.

Un impacto de este tipo fue el que vivió, por ejemplo, una de las figuras centrales del movimiento liberacionista latinoamericano: el célebre obispo Hélder Câmara quien, siendo inicialmente un típico integrista, partidario del corporativismo, siempre declaró que fue gracias a la lectura de Maritain difundido en Brasil por Alceu Amoroso Lima quien fue el traductor de sus obras al portugués- cómo realizó su propio pasaje del integrismo a la concepción democrática. Pero Câmara, no se detendrá en el estadio demócrata cristiano de la recepción de Maritain, sino que avanzará en su potencial neomodernista o perfectista de diálogo con el marxismo precisamente el aspecto de Maritain criticado por Del Noce- que será también luego el itinerario de muchos de los precursores de la teología de la liberación en toda la región.

Por lo demás, la llegada de varias figuras europeas desembarcadas en América Latina, será clave para acelerar este pasaje del maritainismo meramente político - liberal o demócrata cristiano- al maritainismo o postmaritainismo social y económico de izquierda. En primer lugar, sin duda influirá el arribo del padre Lebret quien, como ya señalamos, traerá de Francia su inmenso impulso de reformista social desarrollista cristiano inspirado en la nueva teología social de Le Saulchoir en diálogo con el marxismo. De hecho, Lebret entrará en contacto estrecho con Hélder Câmara (Artigas de Godoy, 2020) y con los maritainianos de toda América Latina impulsándolos, durante los años cincuenta y sesenta, a llevar adelante un programa de desarrollo social y económico local, regional y nacional a gran escala. Sin embargo, esta inmensa expectativa de transformación estructural como fruto del programa lebretiano, se verá abruptamente interrumpida por la muerte de Lebret en 1966 y por la crisis general del proyecto desarrollista en el continente que derivará en el último paso que darán muchos maritainianos: el camino de una revolución socialista inspirada en el modelo cubano.

En efecto, a esta primera etapa que culmina con la crisis del desarrollismo cristiano, le sucederá una segunda etapa de adopción lisa y llana del marxismo como metodología de análisis y praxis teológico-social por parte de muchos maritainianos latinoamericanos. En esta etapa serán otras figuras europeas mucho más cercanas al marxismo que Lebret -como los 
padres Bigo, Comblin, Loew o Girardi-, quienes prepararán el terreno para la llegada de los teólogos latinoamericanos propiamente dichos.

De hecho, aunque ha sido poco estudiada, la influencia inicial de Maritain en teólogos y filósofos de la liberación como Gutiérrez, Boff, Assmann o Dussel (este último fue, de hecho, el autor de una primera tesis en Francia sobre el tema del bien común en el pensamiento de Maritain) es un hecho comprobado. Todos ellos, nucleados por Câmara, romperán a fines de los años sesenta con el planteo desarrollista de Lebret y se pronunciarán en favor de una teología en íntima relación con el marxismo como programa intelectual de una revolución social y eclesial -muchas veces violenta- que considerarán necesaria para el continente. El resto de la historia es conocida: la famosa conferencia del episcopado latinoamericano de Medellín, el surgimiento de la teología de la liberación, la deriva de las corrientes más radicales en dirección a la violencia, la llegada a la sede de Pedro de Juan Pablo II y su mandato a poner fin al diálogo con el marxismo, los documentos duramente críticos de Ratzinger, y la decadencia o pérdida del fermento marxista en la teología de la liberación que derivará en su fragmentación subsiguiente en diversas teologías ecologistas, indigenistas o feministas.

Asimismo, atravesando la pequeña puerta al marxismo abierta por Maritain, y por influencia directa o indirecta de los teólogos de la liberación y del clima de diálogo con el marxismo, los teólogos argentinos del pueblo como Gera, Tello o Scannone- también absorberán, aunque con mayores reservas debido a su adhesión al peronismo, una buena parte de las tesis económicas, sociológicas e históricas del marxismo latinoamericano en el primer tramo de sus orígenes (Hoevel, 2021). Por lo demás, tanto el paso del tiempo como la conflictiva represión de la deriva marxista en el pensamiento y la praxis pastoral y política de muchos católicos en todo el continente, irán haciendo olvidar este rol de intermediación original de Maritain -tan fuertemente criticado por Del Noce- reubicando más bien su figura como el referente de los moderados de la democracia cristiana latinoamericana.

\section{A modo de conclusión: el arrepentimiento por una puerta imprudentemente abierta y la vigencia de la crítica de Del Noce en la actualidad}

Gracias, sobre todo, pienso, a Emmanuel Mounier -escribirá Maritain a fines de la década del sesenta- la expresión “personalista y comunitaria” se ha vuelto una tarta de crema para el pensamiento católico y la retórica católica francesa. Yo mismo no dejo de 
sentirme, en parte, también responsable. En una época en la que era importante oponer a los slogans totalitarios otro slogan, pero verdadero, empleé gentilmente mis células grises y finalmente adelanté en uno de mis libros de aquel tiempo la expresión de la que hablamos; y es de mí de quien creo Mounier la sacó. Es justa; pero viendo el uso que de ella se hace ahora, ya no me siento tan orgulloso. Ya que después de haber pagado un lip service al "personalismo" está claro que es lo "comunitario" lo que gana (Maritain, 1966: 82).

Lo que parece evidenciar esta declaración tardía de Maritain en su Le paysan de la Garonne, es que si bien él siempre actuó frente a las autoridades eclesiales, a la vez como mediador y protector de Mounier y de Esprit embarcados en una línea cada vez más de izquierda en diálogo con el marxismo- finalmente, terminará siendo un claro opositor de esta misma tendencia. Pero estas palabras expresan también en qué medida él mismo percibía su propia responsabilidad en la deriva del personalismo hacia un comunitarismo que terminaría en muchos casos en una alianza, para él imposible, con el marxismo. De hecho, el Maritain anciano será testigo asombrado -bajo la mirada atenta y compasiva de su admirador y a la vez crítico Del Noce- de la verdadera avalancha de fervor marxista entre los cristianos que inundará la Iglesia en los años del Concilio y el post-Concilio (Garaudy, 1965), llevando a un extremo inesperado de radicalización teológico-política, su tímida apertura al marxismo de décadas anteriores.

Lo cierto es que, con el correr del tiempo, Del Noce atenuará sus críticas al maestro, valorando cada vez más su rol de conciliador de la Iglesia, no ciertamente con el marxismo, sino con la modernidad política en general y con la democracia en particular. Por otra parte, tampoco ignorará la variedad de modos de recepción e interpretaciones de Maritain ni estará nunca entre sus intenciones querer "teñir de rojo" el conjunto de la obra de este último. No obstante, esta valoración generalmente positiva de su pensamiento no implicará en Del Noce un arrepentimiento de su crítica de un error histórico que, en su opinión, marcaría el tono de la evolución de una gran parte de la Iglesia y la sociedad en la segunda mitad del siglo XX.

Por lo demás, alguien podría preguntarse qué tipo de interés puede tener esta vieja crítica de Del Noce a Maritain en la situación eclesial y social actual. Mi impresión es que dicha crítica sigue vigente en la medida en que existen en la actualidad en algunos sectores de la Iglesia, en alianza con representantes de las elites globales, ciertas señales de resurgimiento de un 
movimiento de efervescencia teológico-política con ambiciones de encabezar una gran transformación social. Sobre una base bastante ecléctica de ideas sociológicas y éticas de distintas procedencias, combinadas con ideas teológicas y secularistas y con restos fragmentarios y dispersos del marxismo, dicho movimiento busca realizar la crítica del capitalismo global actual y proponer una nueva opción histórica para la sociedad. Para ello, sus promotores parecen volver sobre ciertos viejos temas de resonancia socialista-cristiana, como la crítica de la burguesía (o del "egoísmo de la clase media”), la exaltación de una clase popular redentora y una insistencia en querer dejar definitivamente en el pasado una sociedad económica y cultural liberal concebida solo como error ("olvido de la historia" la llamaría Del Noce).

Imbuido de cierta expectativa milenarista ("deificación de la historia futura” en el lenguaje delnociano), dicho movimiento, parecería asimismo vislumbrar en un futuro cercano algún tipo de salto histórico sucedáneo de lo que en su momento representaba la idea de revolución (Del Noce, 2004). En la creencia de que el mundo se estaría encaminando a una catástrofe ambiental y social inminente, los partidarios de este movimiento parecen abrigar la convicción de que la cercanía al desastre obliga a la humanidad a dar un paso hacia un estadio histórico ética y socialmente superior: un evento que podría dar nacimiento a una nueva sociedad que, aunque exigiría un sacrificio de la libertad, permitiría superar los males de la actual sociedad neoliberal (como la desigualdad, las guerras, las migraciones), expectativa que se justificaría aun más desde el advenimiento de la pandemia. En tal sentido, la vieja crítica de Del Noce al germen perfectista promovido en su momento más o menos involuntariamente en la Iglesia por Maritain, parece recobrar hoy una inesperada actualidad.

\section{Referencias Bibliográficas}

Artigas de Godoy, J. H. (2020). "Dom Helder Câmara e Louis-Joseph Lebret: Desenvolvimentismo e Práxis Progressista Católica nas Décadas de 1950 e 1960". Dados, 63 (1), 1-41.

Avon, D. (2005). "Une école théologique à Fourvière?". In Les jésuites à Lyon: xvie-xxe siècle [en línea]. Lyon: ENS Éditions.

Borghesi, M. (2011). Augusto Del Noce: La legittimazione critica del moderno. Milano: Marietti.

Bressolette, M. (1997). "La foi qui sépare ou les épreuves de l'amitié entre Charles Péguy et Jacques Maritain". Cahiers de l'Association internationale des études francaises, $\mathrm{n}^{\circ} 49,371-387$.

Chenu, M. D. (1960). Hacia una teología del trabajo. Barcelona: Estela. 
Chenu, M. D. (1985). “Une école de théologie: Le Saulchoir”. En Une école de théologie: Le Saulchoir (editado por G. Alberigo). Paris: Du Cerf, pp. 93-176.

Cottier, G., Morati, L., Pellegrino, U., \& Possenti, V. (1979). Maritain e Marx. La critica del marxismo in Maritain. Milano: Massimo.

Curtis, D. E. (1997). The French Popular Front and the Catholic Discovery of Marx. Hull: University of Hull.

Del Noce, A. (1965). Riforma cattolica e filosofia moderna. 1. Cartesio. Bologna: Il Mulino.

Del Noce, A. (2004). Il suicidio della rivoluzione. Torino: Aragno.

Del Noce, A. (2010) [1964]. Il problema dell'ateismo. Bologna: Il Mulino.

Del Noce, A. (2015) [1970]. L'epoca della secolarizzazione. Torino: Aragno.

De Lubac, H. (2011) [1944]. El drama del humanismo ateo. Madrid: Encuentro.

Desrosches, H. C. (1949). Signification du marxism. Paris: Editions ouvrières.

Fessard, G. (1959). De l'actualité historique (Tome II: Progressisme chrétiene et apostolat ouvrier). Paris: Desclée.

Fessard, G. (1979). Teología de la Liberación: génesis y trayectoria (El pensamiento de Julio Girardi). Caracas: Universidad Católica Andrés Bello.

Garaudy, R. (1965). De l'anathème au dialogue. Un marxiste s'adresse au Concile. Paris: Plon.

Hoevel, C. (2021). "La teología del pueblo: orígenes, ideas e interpretaciones". Communio Arg., XXVII (3), 91-123.

Houée, P. (1997). Louis Joseph Lebret. Un éveilleur d'humanité. Paris: Éditions de l'Atelier.

Lebret, L.-J. (1958). "Développement harmonisé et économie humaine”. Economie et Humanisme, $\mathrm{n}^{\circ} 113$.

Löwy, M., \& Garcia-Ruiz, J. (1997). "Les Sources françaises du christianisme de la libération au Brésil”. Archives de sciences sociales des religions, $\mathrm{n}^{\circ}$ 97, 9-32.

Maritain, J. (1966). Le Paysan de la Garonne: un vieux laïc s'interroge à propos du temps présent. Paris: Desclée De Brouwer.

Maritain, J. (2001) [1936]. Humanismo integral. Madrid: Palabra.

Rémond, R. (1978). "L'intelligentsia catholique française et le marxisme". Les quatre fleuves, $\mathrm{n}^{\circ} 8,74-77$.

Scannone, J. C. (1982). "La teología de la liberación. Caracterización, corrientes, etapas". Stromata, $\mathrm{n}^{\circ}$ 38, 3-40.

Tranvouez, Y. (2000). Catholiques et communistes. La crise du progressisme chrétien, 1950-1955. Paris: Cerf.

${ }^{1}$ Agradezco a Ricardo Delbosco, Andrés Di Ció, Alberto Espezel, Aníbal Fornari, Álvaro Perpere, Enrique Serra y Cecilia Sturla por sus comentarios, aportes y críticas a los borradores previos de este artículo. 
${ }_{2}^{2}$ Es interesante señalar el rescate que realiza Del Noce, entre los miembros de la revista Esprit, de la figura de Paul-Louis Landsberg, discípulo judío alemán de Scheler y asesinado en un campo de concentración nazi, a quien considera "indudablemente la cabeza más filosófica" (Del Noce, 2010: 552, nota 6) y por tanto más libre de este cierto obnubilamiento con el marxismo.

3 "Observamos, en efecto, -escribe Del Noce- que existe una conciliación en Maritain con los valores políticos modernos, pero para nada con la filosofía moderna; bastante coincidencia entre la radicalización máxima de la condena a la filosofía moderna, en el retorno a un tomismo puro, en cierta forma un tomismo existencial contra el tomismo esencialista de los comentadores (de allí su cercanía a Gilson) y la conciliación con los valores ético-políticos que han sido puestos a la luz por el mundo moderno, pero que pueden ser salvados solo por un retorno al tomismo puro" (Del Noce, 2010: 530).

4 "Sería un estudio útil -escribe Del Noce- determinar la línea necesaria de decadencia del pensamiento filosófico-político católico francés, de Maritain a Mounier y luego a Teilhard, producida por aquel primer germen de error que señalamos en la posición de Maritain" (Del Noce, 2010: 557, nota 11).

5 "El P. Marie-Dominique Chenu no dijo otra cosa cuando escribió, a principios de los años ochenta: 'en adelante, gracias a mis compromisos apostólicos y a la luz del Concilio, coloco en primer lugar una teología que emana, antes que de cualquier conceptualización científica, de la fe vivida del Pueblo de Dios, cuya praxis histórica entra en la comprensión de la fe [...]. Entre los teólogos que me acompañaron y me iluminaron en este itinerario, le doy un buen y bello lugar al Padre Gutiérrez, cuya teología de la liberación es un ejemplo eminente de esta nueva teología'. De esto se hizo eco la reflexión del padre Yves Congar unos años después: 'Estas Iglesias, que pronto representarán un tercio, numéricamente hablando, del catolicismo mundial, tienen algo que decir a los demás [...]. Estas experiencias cristianas expresadas por los teólogos de la liberación son un desafío para nosotros. En este sentido, creo que tienen un valor general, aunque no se puedan trasladar a todas partes"' (Houée, 1997, citado por Löwy \& García-Ruiz, 1997: 118119).

6 "Se encuentra este error también en las obras de estudiosos verdaderamente insignes. Así, leyendo el libro extremadamente valioso del P. H. De Lubac, El drama del humanismo ateo, no se puede no sorprenderse por la enorme importancia que da al ateísmo de Feuerbach, al punto de reconducir a éste no solamente el ateísmo de Marx, sino también el de Comte y el de Nietzsche [...] pero una vez reducido el ateísmo de Marx al feuerbachiano, se vuelve posible separar del ateísmo una parte sociológica y política de su obra” (Del Noce, 2010: 131; 90). 